From the Stockholms Sjukhem Foundation, Research and Development Unit/Palliative Care; The Department of Learning, Informatics, Management and Ethics, Medical Management Center, Karolinska Institutet, Stockholm; Department of Neurobiology, Caring Sciences and Society, Division of Nursing, Karolinska Institutet, Huddinge; School of Health and Social Sciences, Högskolan Dalarna, Falun; Department of Public Health and Clinical Medicine, Family Medicine; Umeå Centre for Gender Studies, Research Programme Challenging Gender, Umeå University, Umeå, Sweden; School of Nursing, Midwifery and Social Work, The University of Manchester,

Manchester, United Kingdom; Department of Medical Psychology, Academic Medical Center, University of Amsterdam, Amsterdam, the Netherlands.

Submitted March 28, 2009; accepted November 30, 2009; published online ahead of print at www.jco.org on March 8, 2010.

Supported by Grants No. 3953-B97-01XAB 3953-B9903XAA, 39531300 04XAC, 3953B01-05XBC, and 2006/1026 from the Swedish Cancer Society; No. K2002-27VX 14326-01A and K2003-27P-14871-01A from the Swedish Research Council; No. 99941390 from the Swedish Heart-Lung Foundation; No. V2001-068, V99-010, and V97-029 from the Swedish Foundation for Health Care Sciences and Allergy Research; by the Research Board for Health Care Sciences at Karolinska Institutet, and the National Research School for Health Care Sciences and COOP Sweden.

C.T. and M.L. contributed equally to this article.

Authors' disclosures of potential conflicts of interest and author contributions are found at the end of this article.

Corresponding author: Carol Tishelman RN, PhD, Stockholms Sjukhem, FoUUenheten, Karolinska Institutet,

Mariebergsgatan 22, 11235 Stockholm Sweden; e-mail: carol.tishelman@ki.se.

(C) 2010 by American Society of Clinical Oncology

0732-183X/10/2811-1942/\$20.00

DOI: $10.1200 / J C O .2009 .23 .3403$

\title{
Are the Most Distressing Concerns of Patients With Inoperable Lung Cancer Adequately Assessed? A Mixed-Methods Analysis
}

Carol Tishelman, Malin Lövgren, Eva Broberger, Katarina Hamberg, and Mirjam A.G. Sprangers

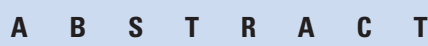

\section{Purpose}

Standardized questionnaires for patient-reported outcomes are generally composed of specified predetermined items, although other areas may also cause patients distress. We therefore studied reports of what was most distressing for 343 patients with inoperable lung cancer (LC) at six time points during the first year postdiagnosis and how these concerns were assessed by three quality-of-life and symptom questionnaires.

\section{Patients and Methods}

Qualitative analysis of patients' responses to the question "What do you find most distressing at present?" generated 20 categories, with 17 under the dimensions of "bodily distress," "life situation with LC," and "iatrogenic distress." Descriptive and inferential statistical analyses were conducted.

\section{Results}

The majority of statements reported as most distressing related to somatic and psychosocial problems, with $26 \%$ of patients reporting an overarching form of distress instead of specific problems at some time point. Twenty-seven percent reported some facet of their contact with the health care system as causing them most distress. While 55\% to 59\% of concerns reported as most distressing were clearly assessed by the European Organisation for Research and Treatment for Cancer Quality of Life Questionnaire Core-30 and Lung Cancer Module instruments, the Memorial Symptom Assessment Scale, and the modified Distress Screening Tool, iatrogenic distress is not specifically targeted by any of the three instruments examined.

\section{Conclusion}

Using this approach, several distressing issues were found to be commonly reported by this patient group but were not assessed by standardized questionnaires. This highlights the need to carefully consider choice of instrument in relation to study objectives and characteristics of the sample investigated and to consider complementary means of assessment in clinical practice.

\section{J Clin Oncol 28:1942-1949. (C) 2010 by American Society of Clinical Oncology}

\section{INTRODUCTION}

Patients with lung cancer (LC) suffer severe symptomatology compared with other groups of cancer patients, ${ }^{1-3}$ in part because of the advanced stages of disease most common at diagnosis. ${ }^{4,5}$ Patients' generally poor prognosis ${ }^{4,6}$ calls for alleviation of distress from diagnosis and throughout the disease trajectory. Cancer-related distress is defined by the U.S. National Comprehensive Cancer Network $(\mathrm{NCCN})^{7}$ as an unpleasant multifactor emotional experience that can cause difficulties for the individual in coping with cancer, physical symptoms, and treatments. Distress is said to extend along a continuum from normal feelings of vulnerability, sadness, and fears to more disabling problems (ie, depression, anxiety, and existential crisis). ${ }^{7}$

The importance of empirically examining symptom-related distress has been frequently acknowledged $^{1,8}$; however, this is rarely done, because studies often focus on symptom occurrence or quality of life (QoL). Recent research points to distress as a distinct dimension of symptom experience, ${ }^{9-11}$ meriting further research. Because questionnaires that assess patient-reported outcomes (ie, symptoms) generally use preformulated sets of questions developed for specific purposes, there may be areas causing distress that are crucial for the individual but not appraised through such standardized questionnaires. 
We encountered this problem early in data collection using predefined questionnaires in a sample of patients with inoperable LC. Many patients described distress that was not adequately assessed by our instrument battery. ${ }^{9}$ We therefore complemented data collection with an open question that examined what concerns patients with inoperable LC spontaneously reported as most distressing. We investigated what patients reported as most distressing during the first year following diagnosis and in relation to time to death. We also examined the extent to which these concerns are assessed by common QoL/ symptom questionnaires.

\section{PATIENTS AND METHODS}

The project was approved by the relevant research ethics committee (Karolinska Institutet registration number 97-258, appendices 990503, 010220, 010731, and 021212). This study is based on data from 343 patients with inoperable LC consecutively recruited close to diagnosis (median, 25 days; mean, 32 days) through the lung medicine departments of two university hospitals in the Stockholm region (Appendix Tables A1 and A2, online only, provide details on patient accrual and attrition). Staff were asked to inform each patient about the study and provide written information, with a copy also sent by mail to each patient's home. A research nurse then contacted each patient by telephone to provide further information, answer questions and, if the patient was willing to participate, obtain informed consent and schedule the first interview at a venue of the patient's choice. Data were collected through a nurse-led interview at six time points: close to diagnosis and before treatment (T1), 2 weeks after T1 (T2), and 1 month (T3), 3 months (T4), 6 months (T5), and 12 months (T6) after T1. After each interview, participants received a 50 sek (approximately USD6.25 or euro5.30) gift certificate donated by COOP Sweden (a national federation of cooperative stores).

Each interview began with an open question "What do you perceive as most distressing at present?" inspired by a freelisting approach. ${ }^{12}$ "Freelisting" derived from anthropology-allows identification of relevant issues uncolored by researchers' assumptions. Patients were asked to spontaneously provide up to five concerns they found most distressing, without further definition or instruction from the interviewer. Responses varied from single words to sentences and were documented in field notes by the research nurse using direct quotes when possible. Each interview continued with the established battery of predefined instruments as reported elsewhere. ${ }^{9,13,14}$ Demographic and clinical data were obtained from patients and registry data.

\section{Data Analysis and Coding}

Data analysis consisted of initial inductive analyses of the raw qualitative data followed by statistical analyses in line with the analytic framework for mixed methods of Onwuegbuzie and Teddlie. ${ }^{15}$ All concerns reported as most distressing were first inductively coded by two interviewers on the basis of similarity in content. ${ }^{16} \mathrm{~A}$ team member who had not participated in patient interviews (M.L.) then led an extended process of repeatedly renegotiating exclusive definitions for each category to increase clarity in categorization and developing a final coding scheme (Table 1), with 19 categories grouped under three dimensions- "bodily distress" (seven categories), "life situation with LC" (nine categories), and "iatrogenic distress" (one category) — and single categories "other specific diseases" and "no distress." Longer statements containing more than one concern were sorted into multiple codes and/or categories, although each category was exclusive and no single issue was coded into more than one category. Ten unclear statements were grouped together ("unspecified concerns/distress"). The final intercoder percent agreement for three pairs of independent raters for a random selection of $5 \%$ of statements using this coding scheme showed $93 \%$ total agreement. There was 100\% agreement for 13 categories, between $83 \%$ and $90 \%$ agreement for five categories: "sickness as a whole" (90\%), "iatrogenic distress" (88\%), "limitations in daily life," "outlook," and "other specific diseases" (83\%). Only one category ("other somatic problems") showed less agreement (67\%) between coders. To account for random agreement, Cohen's kappa was also calculated and ranged between 0.93 and 0.95 between the rater pairs $(P<.001$ in all analyses).

\section{Coding of Freelisting Statements in Relation to Standardized Questionnaires}

We chose three self-completion questionnaires widely used with cancer patients: a QoL instrument (European Organization of Treatment and Research for Cancer Quality of Life Questionnaire Core-30 and the Lung Cancer Module [EORTC-QLQ-C30 + LC13]), ${ }^{17-19}$ a symptom assessment scale (Memorial Symptom Assessment Scale [MSAS] $),{ }^{10,11}$ and a modified Distress Screening Tool (DST) ${ }^{20}$ based on the NCCN definition. ${ }^{7}$ An overview of topics assessed by each instrument is found in Appendix Table A3 (online only).

All freelisting concerns were coded with regard to each of the three questionnaires as (1) a concern clearly assessed by an item in the questionnaire, (2) a concern that might be interpreted as assessed by an item in the questionnaire, or (3) a concern clearly not assessed by any item in the questionnaire. The final intercoder agreement for a random selection of $5 \%$ of the concerns between two raters was 98\% for EORTC QLQ-C30 + LC13, 98\% for MSAS, and $96 \%$ for DST. Cohen's kappa was $0.96(P<.001)$ between both raters for EORTC QLQ-C30 + LC13 and MSAS and $0.93(P<.001)$ for DST.

\section{Analysis of Freelisting Statements During the First Year Postdiagnosis and in Relation to Time of Death}

Demographic and clinical characteristics were examined descriptively. To obtain what Onwuegbuzie and Teddlie ${ }^{15}$ call "frequency effect size," we examined number and proportions of patients reporting most distress for each dimension and category at one or more time points during the first year postdiagnosis. Concerns reported as most distressing are described by time point for a fixed-interval frequency effect size, as described by Onwuegbuzie and Teddlie. ${ }^{15}$ To heighten clinical relevance, we also examined the most distressing concerns expressed in the last interview with each patient. To that purpose, patients were divided into six subgroups using the interval of time from last interview to death (ie, from $>1$ year to $<31$ days from death). To reduce multiple testing, we compared only the two extreme groups (ie, $>1$ year $v<31$ days survival postinterview) using $\chi^{2}$ tests (number of concerns per category) and an independent sample $t$ test (average number of concerns).

\section{Analysis of Freelisting Statements in Relation to Questionnaires}

The percentage of concerns elicited by freelisting that were also assessed by EORTC QLQ-C30 + LC13, MSAS, and DST were calculated. Because the descriptive data suggested possible age-related differences, $\chi^{2}$ tests were used to investigate possible differences in type of distress reported most frequently, and $t$ tests were used to investigate how these instruments assessed concerns of patients younger than age 65 years versus patients age 65 years or older. The significance level was set at 0.05 in all analyses.

\section{RESULTS}

\section{Patient Characteristics}

As summarized in Table 2, the sample is evenly distributed between men and women, although women were significantly younger and less often lived with a spouse. Most patients were diagnosed with non-small-cell lung cancer in advanced stages and received chemotherapy either alone or in combination with radiotherapy.

This sample differs from population data of patients diagnosed with inoperable LC in the same region during this time period in the Stockholm-Gotland Cancer Registry. Our sample was younger (mean age, 64.5 years $v 68.8$ years $[\mathrm{n}=2,375]$ ) and survived longer (mean, 273 days $v 178$ days $[\mathrm{n}=1,975]$ ) than the registry population, which may reflect the inclusion of patients diagnosed in late stages in nonuniversity hospital settings in the Registry.

\section{Most Distressing Concerns}

Table 1 presents the entire coding scheme, including overarching dimensions with their subordinate categories, exemplified by typical 
Table 1. Number and Percentage of Patients $(n=343)$ Who Reported Most Distress at One or More Time Points During the First Year Postdiagnosis, by Dimensions and Categories

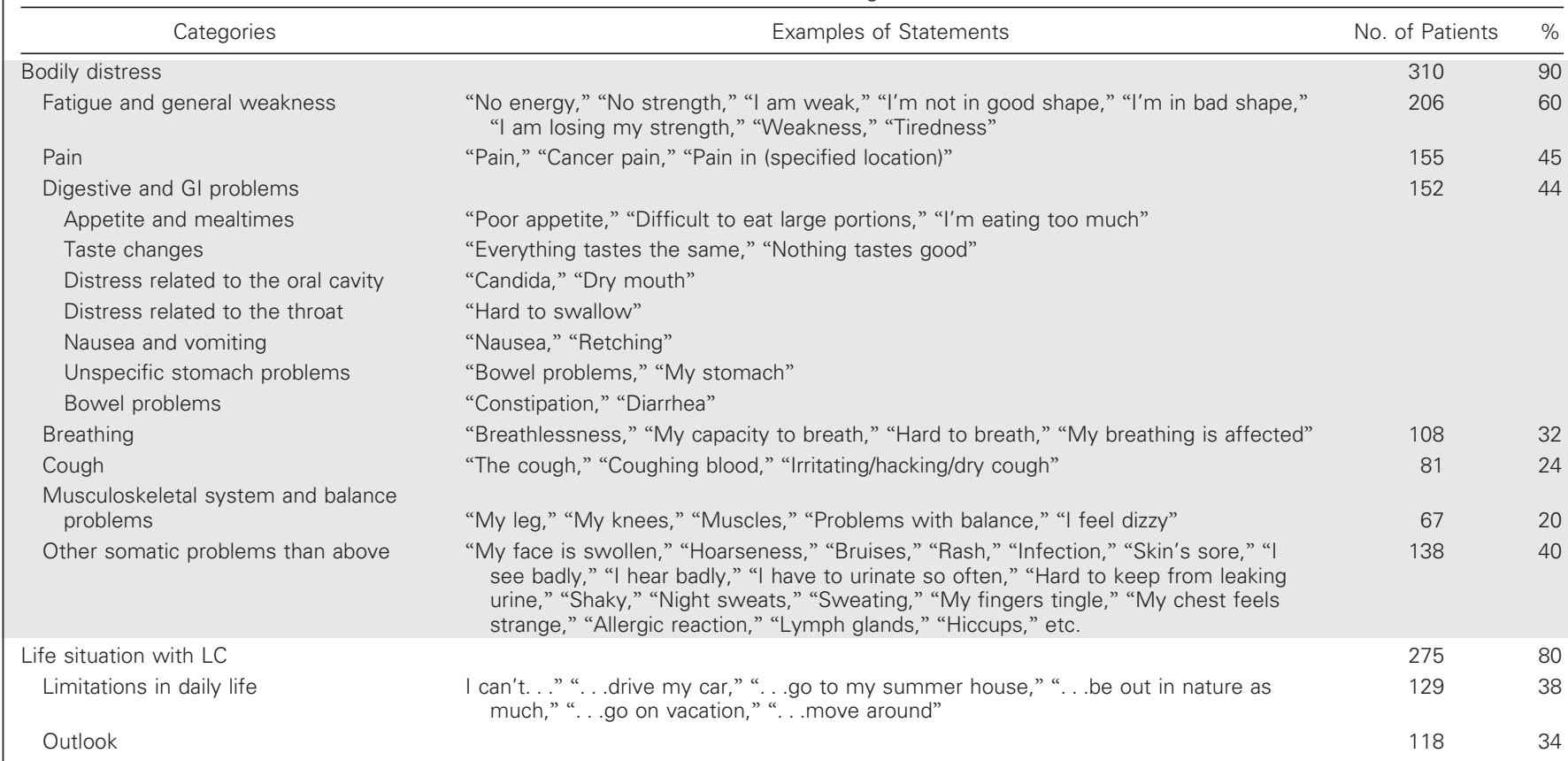

General uncertainty/worry/fear about the future

Uncertainty/worry/fear related to treatment and its effects; uncertainty/worry/fear about examinations or disease progress and their effects

Uncertainty/worry/fears about death

Sickness as a whole

\section{Relationships}

(contact/interaction/dependency/ thoughts related to family, friends, and/or house pet, or the loss of contacts)

Emotional problems

Insomnia

Appearance

Cognitive problems

Economy

latrogenic distress

Distress related to the health care system

Issues related to time, including waiting times, lack of respect for patient's time, limited time with health care professionals

Communication/Information problems

Organization of care/ambulatory visits

Distress related to treatment and procedures (no specific symptoms or problems specified)

"It is the uncertainty that is worst," "Fear and worry about the future"

"Not knowing how this treatment ends," "The effect of the treatment," "Not knowing how this disease will get on," "Worry about symptoms that. . will come from treatment"

"Fear of death," "Worry about facing death," "Uncertainty about when I will die"

"The whole miserable situation," "Just knowledge about the disease," "The lung cancer," "That I have cancer," "The whole situation"

"I worry about my wife/husband," "It's hard for the family," "My family's suffering," "The loneliness," "Isolation," "I feel like a burden for my family"

"The mental part," "Depression," "It's boring," "I feel down," "I am worried and sad," "The anger," "I keep losing my temper," "Negative thoughts," "Meaninglessness"

"Poor sleep," "Problems sleeping," "Sleeplessness"

"I'm too fat," "I'm ugly and fat," "Weight problem," "Losing weight," "Lost my hair," "Baldness"

"Memory problems," "Hard to concentrate"

"My economy," "Money," "The bills"

istress other than above

Other specific diseases

Unspecified concerns/distress

"Diabetes," "Atrial fibrillation," "Menopause"

"Long waiting times for treatment," "Everything takes such a long time," "The system doesn't work, no coordination (about time)," "Long time to the next contact," "Lack of time with them (health care professionals) and poor continuity," "Bad communication," "I've gotten no information," "The information I got was wrong"

"It is hard to sit in the waiting room and see all the other sick people," "I feel pressured by all the hospital visits," "The system does not work," "Having 13 different doctors at 16 appointments," "Lack of continuity in nurses"

"No distress to speak of"

"All the medicines," "The side effects," "The chemotherapy"

"No distress to speak of"

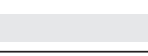




\begin{tabular}{|c|c|c|c|c|c|}
\hline \multirow[b]{2}{*}{ Characteristic } & \multicolumn{2}{|c|}{$\begin{array}{c}\text { Women } \\
(n=169)\end{array}$} & \multicolumn{2}{|c|}{$\begin{array}{c}\text { Men } \\
(n=174)\end{array}$} & \multirow[b]{2}{*}{$P$} \\
\hline & No. & $\%$ & No. & $\%$ & \\
\hline Age, years & & & & & .001 \\
\hline Mean & & & & & \\
\hline SD & & & & & \\
\hline Minimum-maximum & & & & & \\
\hline Median & & & & & \\
\hline Civil status & & & & & .001 \\
\hline Married or cohabiting & 94 & 57 & 128 & 74 & \\
\hline Divorced & 32 & 19 & 20 & 11 & \\
\hline Widow/widower & 28 & 17 & 10 & 6 & \\
\hline Unmarried & 11 & 7 & 16 & 9 & \\
\hline Missing & 4 & & 0 & & \\
\hline Education & & & & & .032 \\
\hline Beyond high school & 78 & 48 & 81 & 48 & \\
\hline High school or equivalent (12 years) & 41 & 25 & 25 & 15 & \\
\hline Less than high school graduate (9 years) & 45 & 27 & 63 & 37 & \\
\hline Missing & 5 & & 5 & & \\
\hline Type of lung cancer & & & & & .89 \\
\hline SCLC & 22 & 13 & 21 & 12 & \\
\hline NSCLC & 145 & 87 & 150 & 88 & \\
\hline Missing & 2 & & 3 & & \\
\hline Stage of disease & & & & & .5 \\
\hline 1 & 4 & 3 & 7 & 5 & \\
\hline$\|$ & 8 & 6 & 4 & 3 & \\
\hline IIIA & 15 & 11 & 14 & 10 & \\
\hline IIIB & 29 & 22 & 37 & 26 & \\
\hline IV & 72 & 54 & 66 & 47 & \\
\hline Unclassified tumor & 6 & 4 & 12 & 9 & \\
\hline Missing & 35 & & 34 & & \\
\hline Treatment received & & & & & .11 \\
\hline Chemotherapy alone & 92 & 54 & 76 & 44 & \\
\hline Radiation therapy alone & 14 & 8 & 25 & 14 & \\
\hline Concomitant chemotherapy and radiation & 21 & 12 & 28 & 16 & \\
\hline Both chemotherapy and radiation & 31 & 18 & 27 & 16 & \\
\hline No treatment & 11 & 7 & 18 & 10 & \\
\hline
\end{tabular}

Abbreviations: SD, standard deviation; SCLC, small-cell lung cancer; NSCLC, non-small-cell lung cancer.

statements. Patients appeared to respond to the interview question without difficulty, with only 38 patients replying at one or more time points that they had no concern that was particularly distressing.

Ninety percent of the patients reported most distress from a concern categorized within the dimension "bodily distress," at one or more time points during the first year postdiagnosis, whereas $80 \%$ and $27 \%$ reported a concern categorized under "life situation with LC" and "iatrogenic distress," respectively, as most distressing during this year (Table 1).

To examine these data further, Figures $1 \mathrm{~A}$ and $2 \mathrm{~A}$ present data by dimension and time point. The mean number of concerns reported as most distressing ranged from 1.9 to 2.5 per person at each time point, with a significantly higher number of average reports in the subgroup closest to death $(P=.037)$ compared with the subgroup with longest survival (Fig 2A).

In the dimension "bodily distress," "fatigue" and "general weakness" were named as most distressing by most individuals at each time point (Figs 1B and 2B). "Pain" was most commonly reported as most distressing in the subgroup closest to death (Fig
2B) and differed significantly $(P=.036)$ from the subgroup surviving $>1$ year after last interview.

In the dimension "life situation with LC," "limitations in daily life" and "outlook" were reported by the greatest number of individuals at all time points (Fig 1C). It is notable that $26 \%$ of patients responded with a composite or overarching statement, categorized as "sickness as a whole," rather than referring to a specific problem or symptom. "Insomnia" was significantly $(P=.008)$ more frequently reported as most distressing in the subgroup closest to death than in the subgroup surviving $>1$ year postinterview (Fig 2C).

\section{Freelisting Statements in Relation to the Questionnaires}

In Table 3, 55\% to 59\% of all statements were judged as clearly assessed by the three instruments evaluated, with an additional $7 \%$ to $9 \%$ of statements possibly assessed. All three instruments captured statements categorized as "bodily distress" most thoroughly, with "musculoskeletal and balance problems" assessed less thoroughly than other concerns in this dimension. Coverage of 


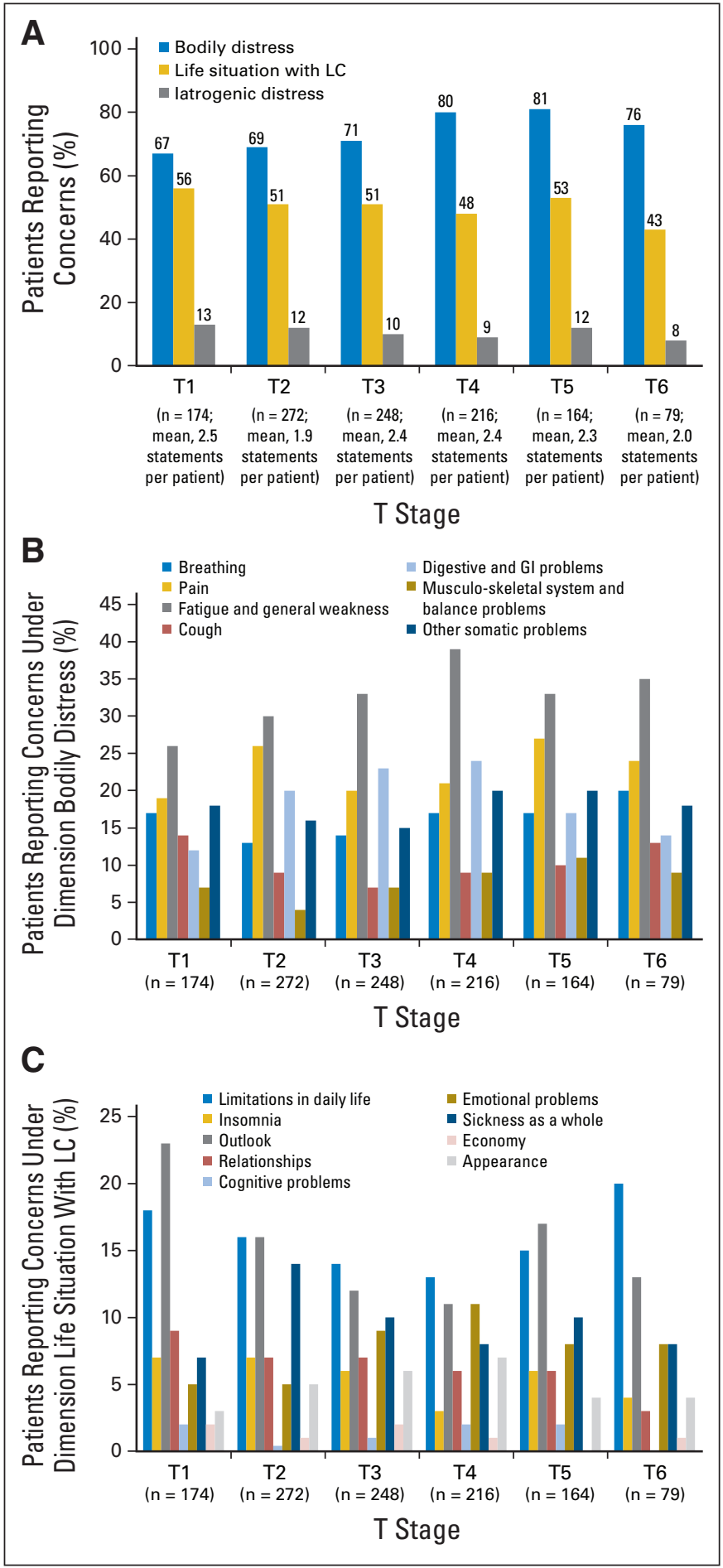

Fig 1. Proportions of patients who reported concerns related to (A) the three dimensions at T1-T6 (time points throughout study) and numbers of mean statements per patient, (B) the different categories under the dimension "Bodily Distress" at T1-T6, and (C) the different categories under the dimension "Life Situation with LC" at T1-T6.

concerns in the category "other somatic problems" varied greatly by instrument (Appendix Table A3 and Table 3), but these were generally somewhat better assessed by MSAS and DST than by the EORTC instruments. Approximately $45 \%$ of concerns related to
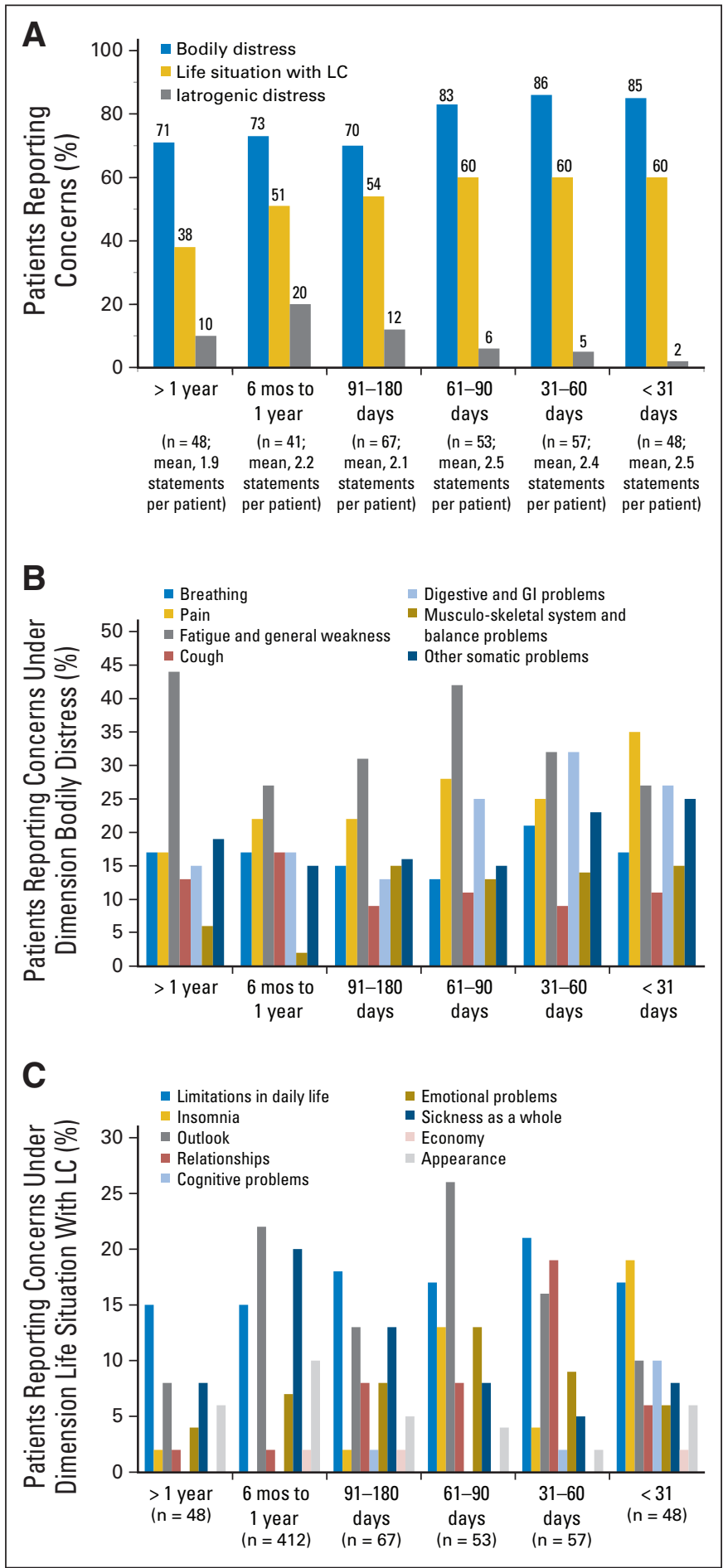

Fig 2. Proportions of patients who reported concerns related to (A) the three dimensions in relation to time of death, and numbers of mean statements per patient, (B) the different categories under the dimension "Bodily Distress" in relation to time of death, and $(\mathrm{C})$ the different categories under the dimension "Life Situation with LC" in relation to time of death.

"life situation with LC" were assessed by the EORTC instruments and DST while MSAS covered approximately $26 \%$, with few iatrogenic concerns assessed by any of these instruments. Because younger patients described significantly more concerns than older 


\begin{tabular}{|c|c|c|c|c|c|c|c|c|c|c|c|c|}
\hline \multirow{3}{*}{$\begin{array}{l}\text { Total No. of } \\
\text { Statements } \\
\text { (T1-T6)* }^{*}\end{array}$} & \multicolumn{4}{|c|}{ EORTC QLQ-C30 + LC13 } & \multicolumn{4}{|c|}{ MSAS } & \multicolumn{4}{|c|}{ DST } \\
\hline & \multicolumn{2}{|c|}{ Assessed } & \multicolumn{2}{|c|}{$\begin{array}{c}\text { Might Be } \\
\text { Interpreted } \\
\text { As Assessed }\end{array}$} & \multicolumn{2}{|c|}{ Assessed } & \multicolumn{2}{|c|}{$\begin{array}{c}\text { Might Be } \\
\text { Interpreted } \\
\text { As Assessed }\end{array}$} & \multicolumn{2}{|c|}{ Assessed } & \multicolumn{2}{|c|}{$\begin{array}{l}\text { Might Be } \\
\text { Interpreted } \\
\text { As Assessed }\end{array}$} \\
\hline & No. & $\%$ & No. & $\%$ & No. & $\%$ & No. & $\%$ & No. & $\%$ & No. & $\%$ \\
\hline 1,436 & 1,059 & 73.7 & 104 & 7.2 & 1,112 & 77.4 & 108 & 7.5 & 992 & 69.1 & 100 & 7.0 \\
\hline 222 & 135 & 60.8 & 53 & 23.9 & 152 & 68.5 & 54 & 24.3 & 135 & 60.8 & 53 & 23.9 \\
\hline 179 & 177 & 98.9 & 2 & 1.1 & 177 & 98.9 & 2 & 1.1 & 177 & 98.9 & 2 & 1.1 \\
\hline 111 & 111 & 100 & 0 & & 111 & 100 & 0 & & 0 & & 0 & \\
\hline 86 & 20 & 23.2 & 27 & 31.4 & 20 & 23.2 & 26 & 30.2 & 10 & 11.6 & 19 & 22.1 \\
\hline 201 & 16 & 8.0 & 10 & 5.0 & 56 & 27.9 & 14 & 7.0 & 74 & 36.8 & 14 & 7.0 \\
\hline 75 & 17 & 22.7 & 40 & 53.3 & 11 & 14.7 & 2 & 2.7 & 55 & 73.3 & 3 & 4.0 \\
\hline 87 & 34 & 39.1 & 31 & 35.6 & 34 & 39.1 & 31 & 35.6 & 30 & 34.5 & 30 & 34.5 \\
\hline 64 & 64 & 100 & 0 & & 64 & 100 & 0 & & 64 & 100 & 0 & \\
\hline 59 & 24 & 40.7 & 6 & 10.2 & 39 & 66.1 & 15 & 25.4 & 39 & 66.1 & 11 & 18.6 \\
\hline 15 & 15 & 100 & 0 & & 8 & 53.3 & 0 & & 7 & 46.7 & 8 & 53.3 \\
\hline 14 & 14 & 100 & 0 & & 0 & & 0 & & 0 & & 0 & \\
\hline 123 & 0 & & 3 & 2.4 & 0 & & 3 & 2.4 & 9 & 7.3 & 20 & 16.3 \\
\hline \multicolumn{13}{|c|}{ Other distress } \\
\hline 48 & 3 & 6.3 & 6 & 12.5 & 3 & 6.3 & 6 & 12.5 & 3 & 6.3 & 6 & 12.5 \\
\hline 13 & 1 & 7.7 & 1 & 7.7 & 0 & & 1 & 7.7 & 1 & 7.7 & 1 & 7.7 \\
\hline 2,399 & 1,418 & 59.1 & 214 & 8.9 & 1,317 & 54.9 & 177 & 7.4 & 1,342 & 55.9 & 210 & 8.8 \\
\hline
\end{tabular}

patients in relation to pain $(P=.049)$, insomnia $(P=.032)$, emotional problems $(P=.002)$, appearance $(P=.049)$, sickness as a whole $(P=.001)$, and iatrogenic distress $(P=.05)$, we also investigated differences in the extent to which these instruments assessed concerns of younger (age $<65$ years) and older (age $\geq 65$ years) patients. The most distressing concerns of younger patients were assessed to a significantly lesser extent by items in EORTC QLQ-C30 + LC13 (younger 53\% $v$ older 62\%; $P=.003$ ) and MSAS (younger $49 \% v$ older $57 \% ; P=.005$ ) than those reported by older patients; no age-related difference was noted for DST.

\section{DISCUSSION}

This mixed-methods study used an innovative approach to assess what patients with inoperable LC spontaneously reported as most distressing during the first year postdiagnosis, which is also the last year of life for most of these 343 patients. In line with a study of palliative cancer patients by Riechelmann et al, ${ }^{21}$ concerns reported as most distressing by a large proportion of patients in this study include "fatigue/general weakness" and "pain," with "pain" and "insomnia" more predominant in reports of most distress from the patients with the shortest survival times. The combined impact of emotional and existential issues ("outlook," "sickness as a whole," "relationships," and "emotional problems") was particularly burdensome, with "limitations in daily life" also a distressing aspect of the life situation for many patients. While it is not surprising that the vast majority of patients report experiencing most distress from concerns categorized as "bodily distress" and "life situation with LC," it is especially notable that more than one quarter of this large sample of symptomatic patients close to the end of life report some facet of their contact with the health care system as causing them most distress at one or more time points during this year. Such concerns are not targeted by any of the three instruments examined, which all assessed "bodily distress" to a greater extent than concerns related to "life situation with LC."

Despite similarities, there were also striking differences between these instruments regarding the focus of concerns reported by patients as most distressing. None of the investigated instruments comprehensively assessed the range of issues reported here and categorized as related to "musculoskeletal/balance disturbances," "outlook," or "sickness as a whole." The DST does assess information problems, which is one of several issues categorized here as causing "iatrogenic distress." It is particularly notable that less than one quarter of comments related to "outlook" concerned issues assessed by any of 
these tools, although more than one third of these patients spontaneously reported such issues as most distressing at some time point. DST does not assess cough, and neither DST nor MSAS specifically assess economic issues. MSAS did not thoroughly cover the issues categorized as related to "limitations in daily life" and "cognitive problems." The EORTC instruments more comprehensively assessed "limitations in daily life" than did the other tools but were found to capture distress related to "appearance" to a lesser degree. The DST was found to most broadly capture concerns about "relationships," while the EORTC instrument's ability to assess such issues appears more dependent on interpretation of the relevant items. The DST also assessed concerns distressing to patients of all ages, whereas concerns of older patients were more thoroughly assessed than those of younger patients in both MSAS and EORTC instruments. MSAS may compensate for some limitations by including an open question about additional distressing symptoms, although the term "symptom" may be interpreted by patients as referring exclusively to somatic issues. Moreover, such open questions tend not to be analyzed and reported in scientific literature. It should be recognized that although frequently used in clinical practice, the EORTC instruments were designed to assess QoL in clinical trials rather than problems on an individual level, ${ }^{17,18}$ while MSAS and DST were formulated for individual clinical use. ${ }^{10,20}$

It is notable that while $26 \%$ of patients responded to the freelisting question with a statement categorized as related to "sickness as a whole," instruments, by nature, tend to target distinct problems. It is possible that many otherwise thorough assessments may thus miss an important patient experience, because what was relatively often expressed here as an overwhelming general sickness experience may not be captured through systematic assessment of discrete symptoms or functional disturbances.

Because most studies that investigate patient concerns use standardized instruments (eg, Hill et $\mathrm{al}^{22}$ ), this study complements prior knowledge. We have systematized the views of a large patient sample in a notably hard-to-reach patient group, although the selection bias toward the healthiest of this terminally ill patient group should be recognized. The risk of type 1 error due to multiple analyses should be considered. While we might have lowered the significance level, we chose not to do so to avoid the risk of prematurely dismissing possible relationships in this hypothesis-generating study. We have avoided limitations of other published studies using inductive approaches (eg, the study of palliative care patients by Åstradsson $\mathrm{et}^{2 l^{23}}$ ), which often use small samples of patients with differing diagnoses. It should be noted that there can be many alternative ways to categorize qualitative data. We have therefore made efforts to explicate the analytic process and the categorizations used here and document them in a manner to facilitate testing in other settings or patient groups. Our findings show relative consistency between degree of coverage of concerns reported as most distressing in three differently formulated instruments, al- though the extent to which this is applicable to other instruments should be considered.

The inductive approach used here may not be suitable for largescale clinical trials. However, we suggest that systematic assessment of distress in a consistent form is a much-needed complement to existing symptom and QoL questionnaires, including individualized QoL measures (eg, Schedule for the Evaluation of Individual Quality of Life $[\mathrm{SEIQoL}]^{23 \mathrm{a}}$ ) for improved clinical practice and research. We also would like to highlight that existing measures of satisfaction with care do not address many of the iatrogenic concerns said to be most distressing for these patients (eg, studies by Grunfeld et al, ${ }^{24}$ Heyland et $\mathrm{al}^{25}$ and Lövgren et $\mathrm{al}^{26}$ ). An important message from this study is the need to carefully consider choice of instrument in relation to the objective and characteristics (eg, age) of the sample under investigation. This study also suggests a need for development of new types of modules assessing not only symptom and psychosocial aspects of distress but also distress resulting from contact with the health care system.

As Osse et $\mathrm{al}^{27}$ point out, not all issues distressing patients translate directly into health care needs. Soothill et $\mathrm{al}^{28}$ concluded that many of the needs ranked as "very important" in a survey of 295 patients with heterogeneous cancers were beyond the remit of the health care system. In contrast, we argue that the concerns reported as most distressing by this group of LC patients are generally well within the remit of a well-functioning health care system, although they appear not well dealt with in actuality. It should again be emphasized that we report here not problems that are prevalent or intense, but rather those few issues per person that are reported to be most distressing. Assessment of severe distress is a crucial component in identifying immediate health care needs and thus in provision of high-quality care.

\section{AUTHORS' DISCLOSURES OF POTENTIAL CONFLICTS OF INTEREST}

The author(s) indicated no potential conflicts of interest.

\section{AUTHOR CONTRIBUTIONS}

Conception and design: Carol Tishelman, Malin Lövgren

Administrative support: Carol Tishelman

Provision of study materials or patients: Carol Tishelman

Collection and assembly of data: Carol Tishelman, Eva Broberger

Data analysis and interpretation: Carol Tishelman, Malin Lövgren, Eva

Broberger, Katarina Hamberg, Mirjam A.G. Sprangers

Manuscript writing: Carol Tishelman, Malin Lövgren, Katarina

Hamberg, Mirjam A.G. Sprangers

Final approval of manuscript: Carol Tishelman, Malin Lövgren, Eva

Broberger, Katarina Hamberg, Mirjam A.G. Sprangers

\section{REFERENCES}

1. Cooley ME: Symptoms in adults with lung cancer: A systematic research review. J Pain Symptom Manage 19:137-153, 2000

2. Lidstone V, Butters E, Seed PT, et al: Symptoms and concerns amongst cancer outpatients: Identifying the need for specialist palliative care. Palliat Med 17:588-595, 2003
3. Zabora J, Brintzenhofeszoc K, Curbow B, et al: The prevalence of psychological distress by cancer site. Psychooncology 10:19-28, 2001

4. Alberg AJ, Ford JG, Samet JM: Epidemiology of lung cancer: ACCP evidence-based clinical practice guidelines (2nd edition). Chest 132:29S-55S, 2007 (suppl 3)

5. Scagliotti GV: Symptoms, signs and staging of lung cancer. European Respiratory Monograph, Lung Cancer (Eur Respir Soc) 6:97-105, 2001
6. Pirozynski M: 100 years of lung cancer. Respir Med 100:2073-2084, 2006

7. The National Comprehensive Cancer Network: NCCN Clinical Practice Guidelines in Oncology, Distress Management, 2006 http://www.nccn.org

8. McClement SE, Woodgate $R L$, Degner $L$ : Symptom distress in adult patients with cancer. Cancer Nurs 20:236-243, 1997

9. Tishelman C, Degner LF, Rudman A, et al: Symptoms in patients with lung carcinoma 
distinguishing distress from intensity. Cancer 104 2013-2021, 2005

10. Portenoy RK, Thaler HT, Kornblith $A B$, et al: The Memorial Symptom Assessment Scale: An instrument for the evaluation of symptom prevalence, characteristics and distress. Eur J Cancer 30A:1326-1336, 1994

11. Portenoy RK, Thaler HT, Kornblith AB, et al: Symptom prevalence, characteristics and distress in a cancer population. Qual Life Res 3:183-189, 1994

12. Bernard HR: Research Methods in Anthropology: Qualitative and Quantitative Approaches (ed 4). Lanham, MD, Altamira Press, 2006

13. Tishelman $C$, Petersson LM, Degner LF, et al: Symptom prevalence, intensity, and distress in patients with inoperable lung cancer in relation to time of death. J Clin Oncol 25:5381-5389, 2007

14. Lövgren $M$, Tishelman $C$, Sprangers $M$, et al: Symptoms and problems with functioning among women and men with inoperable lung cancer: A longitudinal study. Lung Cancer 60:113-124, 2008

15. Onwuegbuzie AJ, Teddlie C: Chapter 13. A framework for analyzing data in mixed methods research, in Tashakkori A, Teddlie C (eds): Handbook of Mixed Methods in Social and Behavioral Research. Thousand Oaks, CA, Sage Publications, 2003, pp 351-383
16. Krippendorff K: Content Analysis: An Introduction to Its Methodology. Thousand Oaks, CA, Sage Publications, 2004

17. Aaronson NK, Ahmedzai S, Bergman B, et al: The European Organization for Research and Treat ment of Cancer QLQ-C30: A quality-of -life instrument for use in international clinical trials in oncology. J Natl Cancer Inst 85:365-376, 1993

18. Bergman $B$, Aaronson NK, Ahmedzai $S$, et al: The EORTC QLQ-LC13: A modular supplement to the EORTC Core Quality of Life Questionnaire (QLQC30) for use in lung cancer clinical trials-EORTC Study Group on Quality of Life. Eur J Cancer 30A: 635-642, 1994

19. Nicklasson $\mathrm{M}$, Bergman B: Validity, reliability and clinical relevance of EORTC QLO C-30 and LC13 in patients with chest malignancies in palliative settings. Qual Life Res 16:1019-1028, 2007

20. Graves KD, Arnold SM, Love CL, et al: Distress screening in a multidisciplinary lung cancer clinic: Prevalence and predictors of clinically significant distress. Lung Cancer 55:215-224, 2007

21. Riechelmann RP, Krzyzanowska MK, O'Carroll A, et al: Symptom and medication profiles among cancer patients attending a palliative care clinic. Support Care Cancer 15:1407-1412, 2007

22. Hill KM, Amir Z, Muers MF, et al: Do newly diagnosed lung cancer patients feel their concerns are being met? Eur J Cancer Care 12:35-45, 2003
23. Åstradsson E, Granath L, Heedman PA, et al: Cancer patients hospitalised for palliative reasons: Symptoms and needs presented at a university hospital. Support Care Cancer 9:97-102, 2001

23a. O'Boyle CA, McGee HM, Hickey A, et al: The schedule for the evaluation of individual quality of life (SEIQuality of life): Administration manual. Dublin, United Kingdom, Royal Collage of Surgeons in Ireland, Department of Psychology, 1993

24. Grunfeld E, Folkes A, Urquhart R: Do available questionnaires measure the communication factors that patients and families consider important at end of life? J Clin Oncol 26:3874-3878, 2008

25. Heyland DK, Dodek P, Rocker G, et al: What matters most in end-of-life care: Perceptions of seriously ill patients and their family members. CMAJ 174:627-633, 2006

26. Lövgren $M$, Hamberg $K$, Tishelman C: Clock time and embodied time experienced by patients with inoperable lung cancer. Cancer Nurs 33:55-63, 2010

27. Osse BH, Vernooij-Dassen MJ, Schadé $E$, et al: The problems experienced by patients with cancer and their needs for palliative care. Support Care Cancer 13:722-732, 2005

28. Soothill K, Morris SM, Harman J, et al: The significant unmet needs of cancer patients: Probing psychosocial concerns. Support Care Cancer 9:597605, 2001

Get These JCO.org Tools Working for You

Access articles and abstracts, including archival issues from 1983 to today. Browse content by subject category. Link to citations from 1,100+ HighWire-hosted journals. Read articles online before they are issued in print. Receive regular e-mail alerts. Search across ASCO Annual Meeting abstracts.

To subscribe or activate your online access, visit jco.org/subscriptions. 